\title{
EFFECTS OF CULTURAL CONDITIONS ON VESICLE AND CONIDIUM MORPHOLOGY IN SPECIES OF CYLINDROCLADIUM AND CYLINDROCLADIELLA
}

\author{
Pedro W. Crous \\ Department of Plant Pathology, University of Stellenbosch, Stellenbosch 7600, South Africa
}

Alan J. L. Phillips

Plant Protection Research Institute, Private Bag X 134, Pretoria 0001, South Africa

AND

Michael J. WingFiELD

Department of Microbiology and Biochemistry, University of the Orange Free State, P.O. Box 339, Bloemfontein 9300, South Africa

\begin{abstract}
Decrease in osmotic potential of growth media resulted in changes to vesicle and conidial morphology in Cylindrocladium scoparium, C. floridanum and Cylindrocladiella camelliae. Radial growth and the presence of chlamydospores also decreased for these species when the osmotic potential of the growth medium was decreased. Vesicle shape varied on different culture media as well as with age and conditions of incubation. Extended incubation periods induced a change in osmotic potentials of the culture media directly influencing vesicle shape. Carnation-leaf agar is proposed as a standard medium for the characterization of morphological criteria in Cylindrocladium and Cylindrocladiella. Moreover, an incubation period of 7 days at $25 \mathrm{C}$ under alternating light and dark cycles is proposed for vesicle examination.

Key Words: conidial morphology, Cylindrocladiella camelliae, Cylindrocladium floridanum, C. scoparium, osmotic potential, temperature, vesicle morphology
\end{abstract}

The genera Cylindrocladium Morgan and $C y$ lindrocladiella Boesewinkel are characterized by hyaline, cylindrical, $0-1$ or multiseptate conidia, the production of chlamydospores and microsclerotia, and by the formation of an appendage (stipe) at the apex of the conidiogenous apparatus. The stipe terminates in a thin-walled vesicle. Species of Cylindrocladiella have penicillate and subverticillate conidiophores, collarettes at the apex of conidiogenous cells (sensu Sutton, 1980) and non-septate stipes. In contrast, species of Cylindrocladium have only penicillate conidiophores, collarettes are absent, collars (sensu Booth and Murray, 1960) are present, and stipes are septate.

When the genus Cylindrocladium (typified by C. scoparium Morgan; Morgan, 1892) was established, the stipe and vesicle were not considered to be of taxonomic importance and were not mentioned in the generic circumscription.
Sobers and Seymour (1967) described a new species, C. floridanum Sobers \& Seymour, which was primarily distinguished from $C$. scoparium on the basis of stipe branching and vesicle shape. Descriptions of subsequent Cylindrocladium spp. have used the vesicle as an important taxonomic character (Sobers, 1968; Peerally, 1973, 1991; Schoulties et al., 1982; El-Gholl et al., 1986, 1989), while other authors have found this characteristic to be highly variable (Zumpetta, 1976; Hunter and Barnett, 1978; Rossman, 1983) and therefore of questionable taxonomic value.

Bugbee (1962) reported that conidial dimensions of $C$. scoparium varied when the fungus was grown on different substrates. Variability in conidial morphology for Cylindrocladium spp. on different culture media has also been noted by other authors (Sobers, 1968; Alfieri et al., 1972; Zumpetta, 1976; Hunter and Barnett, 1978). An urgent need exists, therefore, for standardization 
of techniques and media used when characterizing species of Cylindrocladium and Cylindrocladiella.

Potato dextrose agar (PDA) containing $\mathrm{KCl}$ ( $\mathrm{KCl}$ medium), which lowers the osmotic potential of the agar (Fisher et al., 1983), is frequently used to determine whether species of Fusarium Link form microconidia in chains and false heads or in false heads alone (Fisher et al., 1983; Nelson et al., 1990). The aim of this study was to determine the effect of osmotic potential on vesicle and conidial morphology in two species of $C y$ lindrocladium and a Cylindrocladiella on PDA, $\mathrm{KCl}$ medium and carnation-leaf agar (CLA) (Fisher et al., 1982). This would enable us to evaluate the stability of vesicle morphology as a taxonomic criterion in species of Cylindrocladi$u m$ and $C y$ lindrocladiella. An attempt was made to select a medium and incubation conditions that can be used for consistent identification of Cylindrocladium and Cylindrocladiella spp.

\section{MATERIALS AND METHODS}

Cultures. - The isolates selected for this study were $C y$ lindrocladium scoparium (PPRI 3989), C. floridanum (PPRI 4140) and Cylindrocladiella camelliae (Venkataramani \& Venkata Ram) Boesewinkel (PPRI 3990). Isolates used are maintained at the Plant Protection Research Institute, Pretoria, South Africa (PREM).

Osmotic potential of PDA. - Osmotic potentials are expressed in Pascal $(\mathrm{Pa})$ units and $-1 \mathrm{MPa}$ potential equals -10 bars. PDA having an osmotic potential of $-0.4 \mathrm{MPa}$ was prepared as described by Nelson et al. (1983). $\mathrm{KCl}$ was added to the medium ( $\mathrm{KCl}$ medium) to give osmotic potentials, before inoculation, of -0.8 , $-1.3,-1.8,-2.2,-3.6,-4.5,-6.9,-8.9$ and -12.0 $\mathrm{MPa}$. The required amounts of $\mathrm{KCl}$ were calculated from the formula of Boyer (1969).

The $\mathrm{a}_{\mathrm{w}}$ (water activity) values for the molal $\mathrm{KCl}$ concentrations are those published by Robinson and Stokes (1959), which were converted using the formula of Prior (1979). Actual osmotic potentials of media in petri dishes were verified with a Wescor 5500 vapor pressure meter (Wescor, Logan, Utah).

Carnation-leaf agar. -CLA was prepared by harvesting carnation leaves from actively growing, nonflowering, pesticide-free carnations. Leaves were cut into $2-\mathrm{cm}$ pieces, autoclaved for $15 \mathrm{~min}$ at $121 \mathrm{C}$ and placed on the surface of $1.5 \%$ water agar in $9-\mathrm{cm}$ plastic petri dishes. Plates contained $25 \mathrm{ml}$ of agar and were stored in the dark at $10 \mathrm{C}$ and used within 7 days. No differences in morphological characteristics of the fungi under consideration were observed on either gas-sterilized or autoclaved carnation leaves.

Effect of osmotic potential on linear growth. - Linear growth of each fungus was measured after 6 days of incubation at $25 \mathrm{C}$ on $\mathrm{KCl}$ medium as well as on a

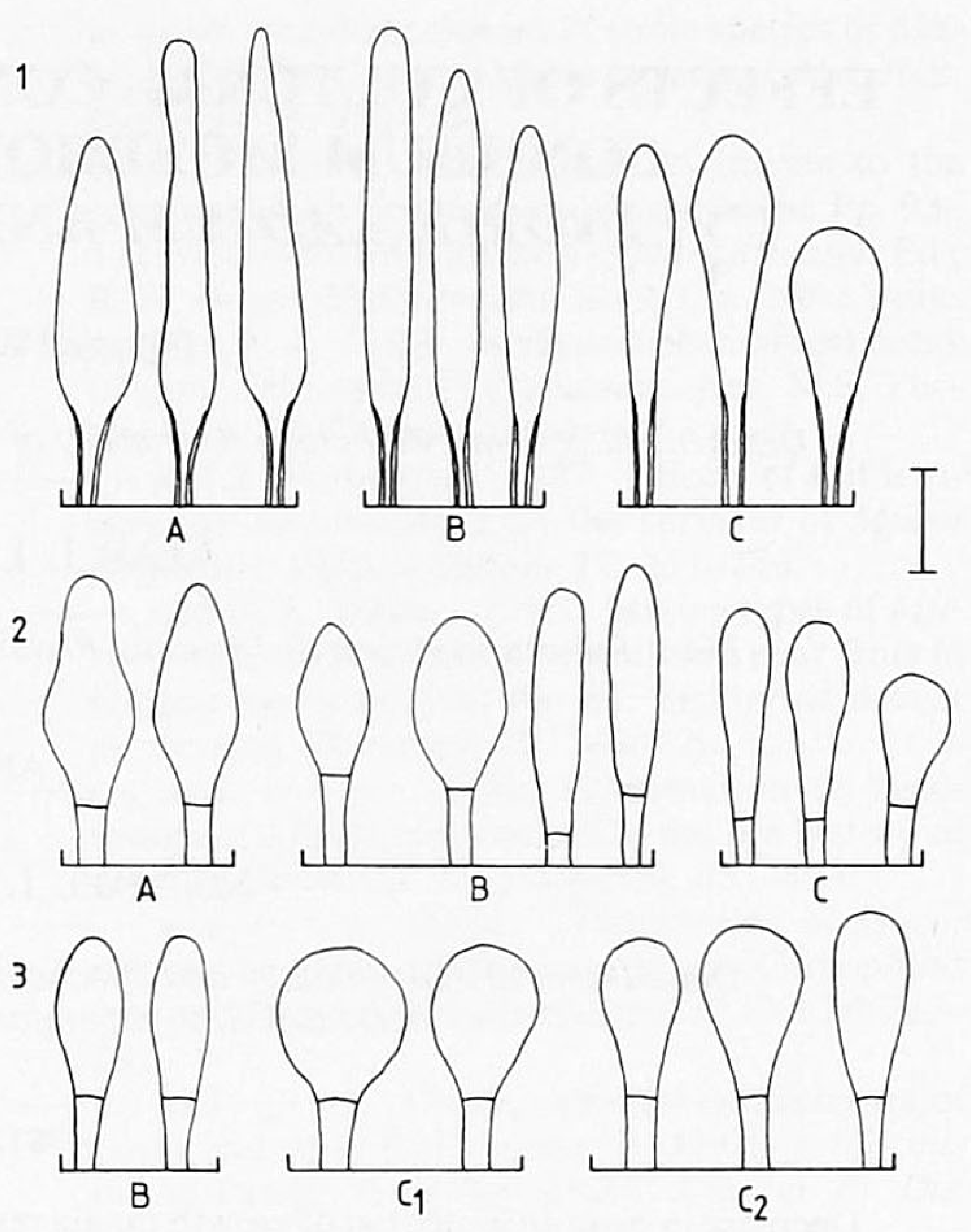

FIGs. 1-3. Variation in vesicle shapes encountered on CLA, PDA and KCL medium. Scale bar $=10 \mu \mathrm{m}$. 1. Vesicles of Cylindrocladiella camelliae. 2. Vesicles of Cylindrocladium scoparium. 3. Vesicles of $C$. floridanum. $\mathrm{A}=$ vesicles widest at the bottom; $\mathrm{B}=$ vesicles widest in the middle; $\mathrm{C}=$ vesicles widest at the apex, with abrupt taper $C_{1}$, and gradual taper $C_{2}$.

control of unamended PDA. All growth studies were conducted using plastic petri dishes with $25 \mathrm{ml}$ of medium per plate. Three plates of each respective medium were used per fungal isolate in all tests. Plates were inoculated with a 3-mm-diam disc of agar from the margin of a 7-da-old colony growing on unamended PDA. To reduce evaporation, plates were sealed with a double layer of Parafilm, and those representing various treatments were placed in separate plastic bags in a single layer under light banks to reduce evaporation (Nelson et al., 1990). An average value was derived by determining the mean of two colony diameters on each of three plates.

Variation in vesicle shape. - Vesicle shape was compared on PDA, $\mathrm{KCl}$ medium and CLA. Plates of the respective media (three per isolate) were inoculated with the three species, as described above, and incubated at $25 \mathrm{C}$ with $12 \mathrm{~h}$ of white light per day. Slides for examination were made from the periphery of each colony after 7 days. For the CLA media, only fungal material occurring on the carnation leaves was examined. Line drawings (Figs. 1-3) of all common vesicle shapes encountered in the three isolates on the various media were made with the aid of a drawing tube.

Three classes of vesicle shape were identified for each species. Vesicles widest at the bottom were placed in 
class $\mathrm{A}$; those widest at the middle in class $\mathrm{B}$; and those widest towards the apex in class C. For C. floridanum, only vesicles widest at the middle or apex were encountered. Those widest at the middle were placed therefore in class B, and those widest at the apex in class C. A distinction was made between those vesicles with an abrupt taper from the apex, $\mathrm{C}_{1}$, and those with a gradual taper, $\mathrm{C}_{2}$ (FIG. 3 ).

After 7 days, 30 vesicles were examined $(100 \times$ objective) from each of three replicates representing the different media. Each vesicle was matched to the closest line drawing (FIGS. 1-3) and assigned to one of the three classes. Only the oldest terminal vesicles on stipes with at least one primary and secondary branch were included. Vesicles that showed signs of any further development (germination, septation or formation of phialides and conidia) were ignored.

Variation in conidium and vesicle size.-Microscopic mounts from PDA, CLA and $\mathrm{KCl}$ media used to rate vesicle shape were also used to measure conidium and vesicle dimensions. Thirty measurements were recorded ( $100 \times$ objective) for conidium length, width, as well as vesicle length and width on each of three replicates for each species. The data were analyzed by Least Significant Difference (LSD) at a probability level of $(\mathrm{P}=$ 0.001 ) after analysis of variance.

Effect of osmotic potential on chlamydospore production. - In Cylindrocladium and Cylindrocladiella, the presence of chlamydospores can be correlated with the number of thick-walled, darkly pigmented, hyphal cells present in culture and hence, degree of culture pigmentation (Hunter and Barnett, 1978). Chlamydospore production was rated as a function of culture pigmentation (viewed from the underside of the plate) and the density of chlamydospores in the medium. Production of chlamydospores and microsclerotia (a cluster of chlamydospores) was based on the extent of thickened, pigmented hyphae after 7 days on PDA and $\mathrm{KCl}$ media incubated at $25 \mathrm{C}$ in the dark. Ratings were as follows: $1=$ dark brown (extensive chlamydospore formation); 2 = medium brown (medium), 3 = caramel brown (fair); 4 = light brown (slight); $5=$ creamy white (few to none). All experiments were replicated three times and repeated at least once.

\section{RESULTS}

Effect of osmotic potential on linear growth.The osmotic potential of the growth medium influenced the linear growth of all three species. Osmotic potentials of $-0.4,-0.8,-1.3,-1.8$, $-2.2,-3.6$ and $-4.5 \mathrm{MPa}$ favored growth of Cylindrocladium scoparium and Cylindrocladiella camelliae, with optimum growth occurring at $-2.2 \mathrm{MPa}$ (FIG. 4). Growth of $C$. floridanum was enhanced at osmotic potentials of -0.4 , $-0.8,-1.2$ and $-2.2 \mathrm{MPa}$, with an optimum at $-1.8 \mathrm{MPa}$. Cylindrocladium scoparium grew at lower osmotic potentials $(-8.9 \mathrm{MPa})$ than $C$. floridanum (FIG. 4).

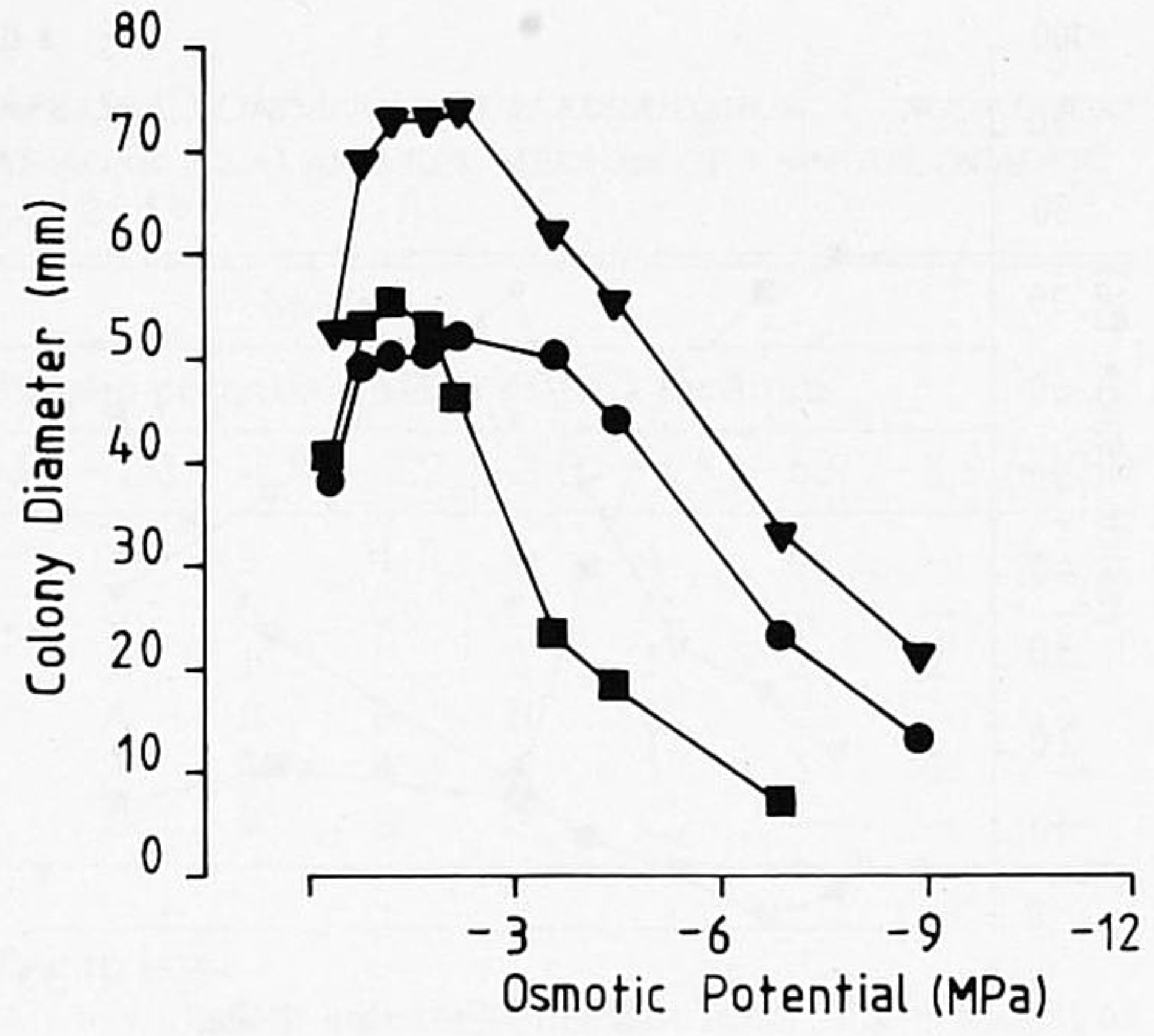

FIG. 4. Influence of osmotic potential of the growth medium on linear growth of $C y$ lindrocladiella camelliae $(\boldsymbol{\nabla})$, Cylindrocladium scoparium $(\bullet)$ and $C$. floridanum ( $\square$ ) after 6 days at $25 \mathrm{C}$ in the dark.

Variation in vesicle shape. - Both Cylindrocladium spp. sporulated sparsely after 7 days on $\mathrm{KCl}$ medium, whereas Cylindrocladiella camelliae exhibited moderate sporulation. Extensive sporulation and vesicle formation was observed for all species on PDA and CLA. Vesicle formation was infrequent for all species on $\mathrm{KCl}$-amended media with osmotic potentials below $-2.2 \mathrm{MPa}$ and sporulation ceased below $-4.5 \mathrm{MPa}$. At -2.2 $\mathrm{MPa}$ and lower, a few of the conidiophores, stipes and vesicles that were formed (not conidia) were plasmolysed.

The most common vesicle shapes observed on $\mathrm{KCl}$ medium varied with a decrease in osmotic potential of the growing medium (FIGs. 5-7). In Cylindrocladiella camelliae vesicles changed from being primarily elliptical and lanceolate (FIGs. 6 , 8 ) to obpyriform. On unamended PDA and on CLA, shapes were frequently hastate as described for $C$. peruviana (Bat., Bez. \& Herrera) Boesewinkel, and even cylindrical, as noted for $C$. infestans Boesewinkel (Boesewinkel, 1982). The most common form was, however, elliptical (TABLE I).

The least obvious change in vesicle shape was seen in Cylindrocladium floridanum, where the vesicle shape varied from napiform (FIG. 9) to more or less sphaeropedunculate (sensu Snell and Dick, 1957) at osmotic potentials of -3.6 and $-4.5 \mathrm{MPa}$ (FIG. 7). No obvious change in vesicle 


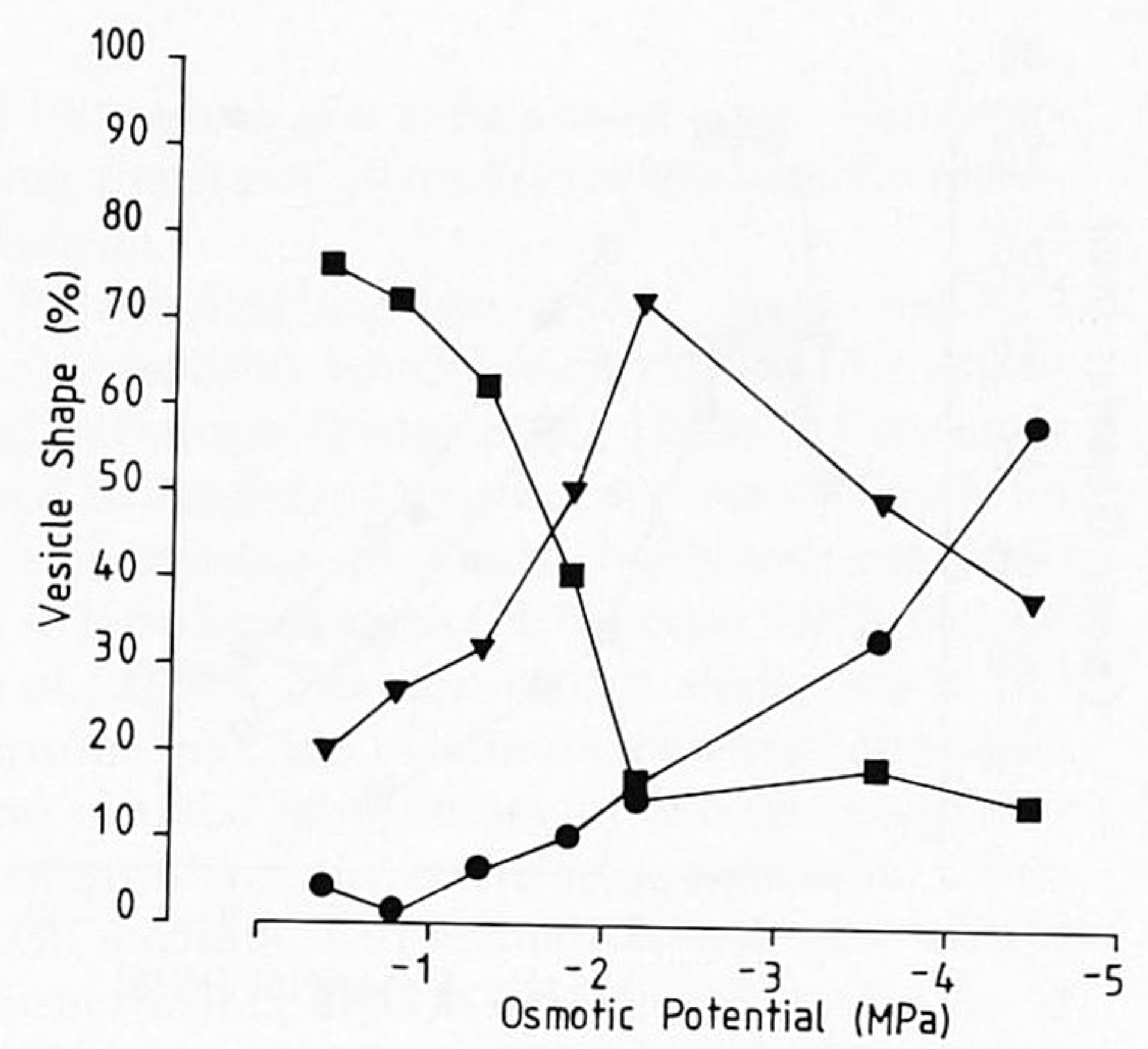

5

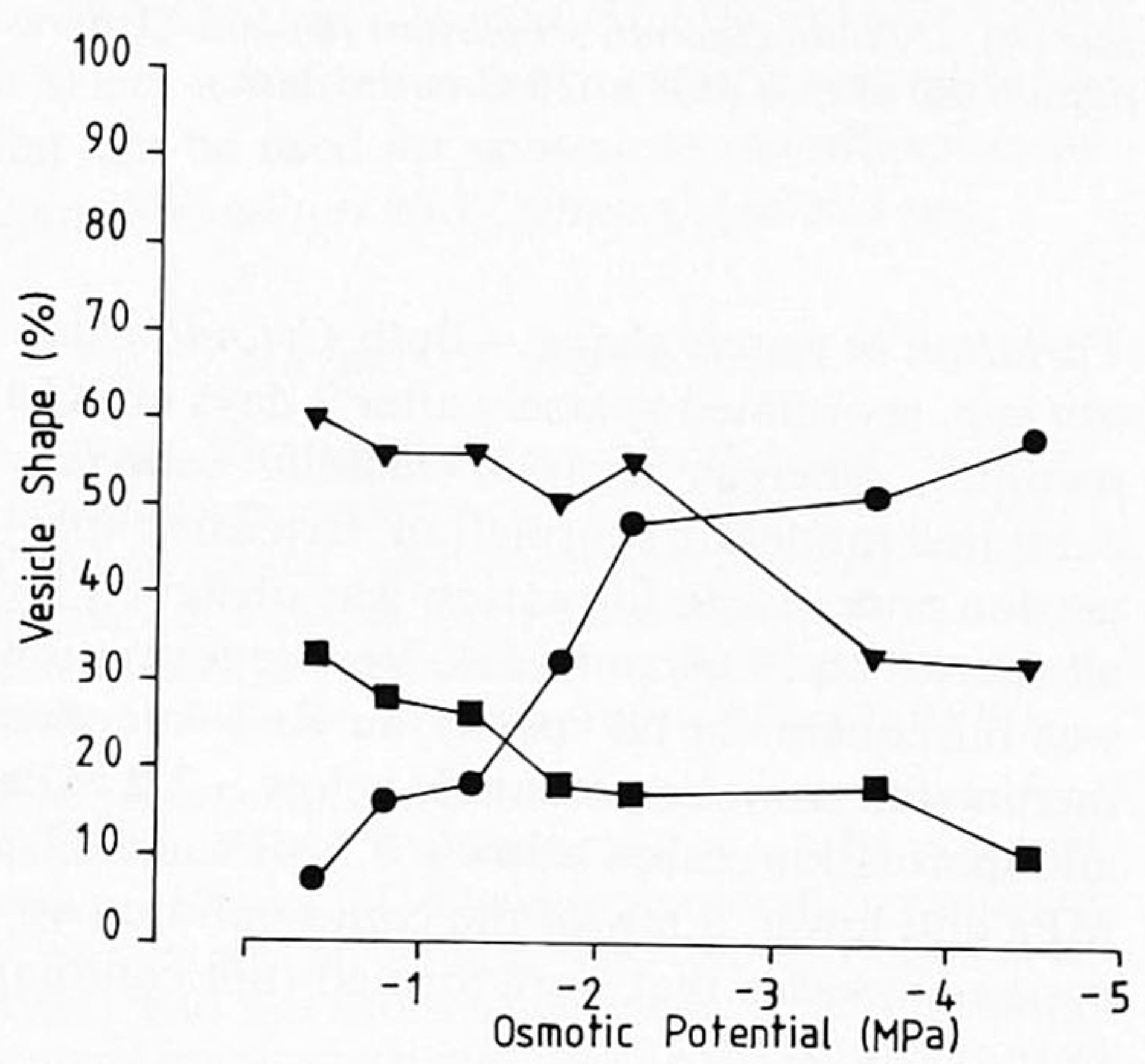

6

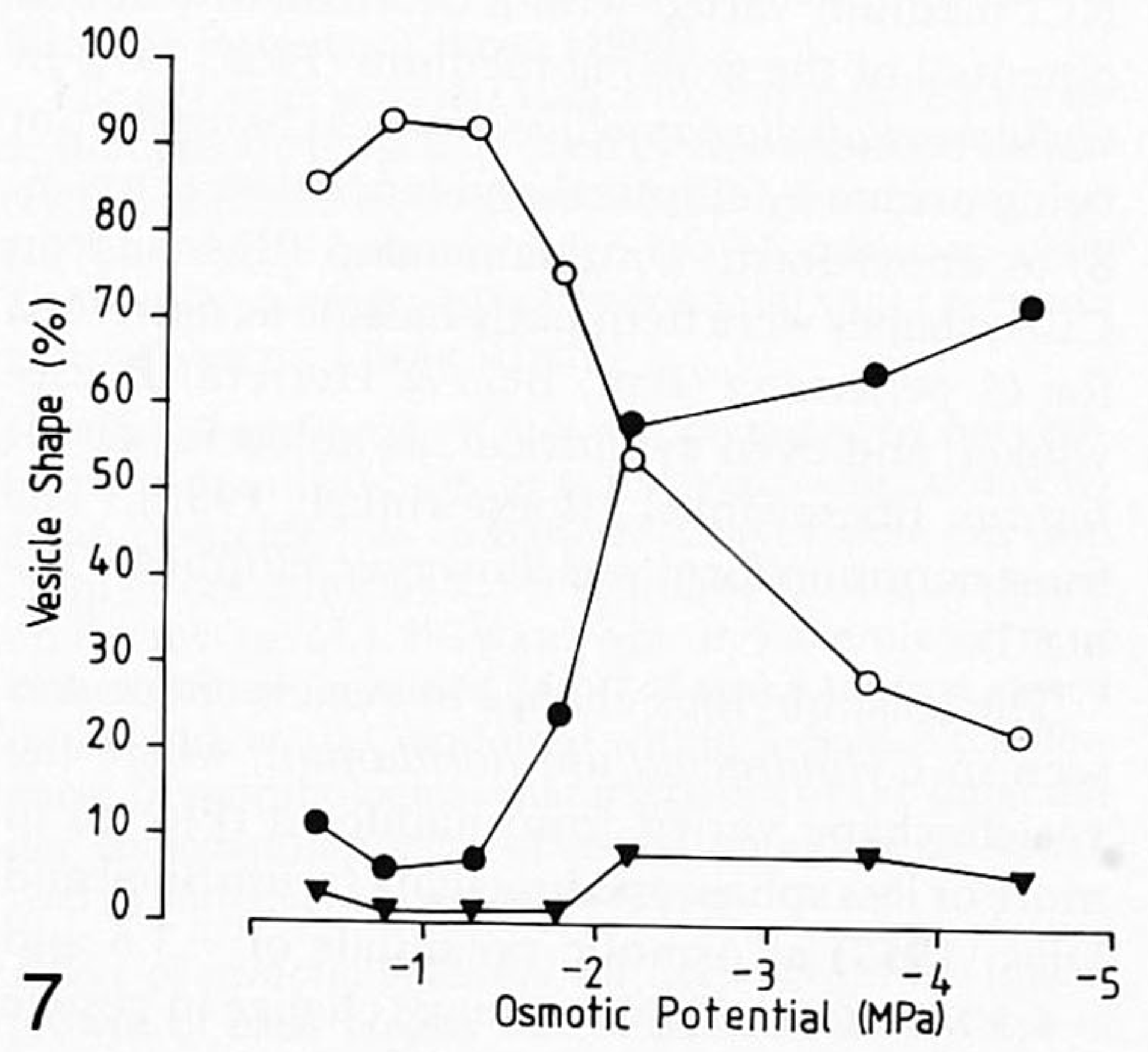

shape was found for this species, irrespective of the media on which it was grown.

On CLA, vesicles of $C$. scoparium were clavate to elliptical or ovate, but on PDA they were obpyriform (FIGS. 10-13, TABLE I). However, on the $\mathrm{KCl}$ media with low osmotic potentials $(-3.6$ and $-4.5 \mathrm{MPa}$ ), vesicles were primarily pyriform (FIG. 5).

Variation in conidium and vesicle dimensions. Conidia and vesicles in both $C$. scoparium and C. floridanum were significantly shorter and narrower on CLA than on PDA (TABLE II). However, conidia and vesicles on $\mathrm{KCl}$ media decreased in size when $\mathrm{KCl}$ concentrations were increased. In contrast, Cylindrocladiella camelliae showed little difference in conidium dimensions or vesicle width between CLA, PDA and $\mathrm{KCl}$ medium. Vesicles were however, much longer on CLA than on PDA. Vesicles in $\mathrm{C}$. $\mathrm{Ca}$ melliae became shorter with increasing amounts of $\mathrm{KCl}$ (TABLE II), similar to the situation for Cylindrocladium spp.

Conidium length, width and vesicle length of Cylindrocladium scoparium and C. floridanum were significantly different on CLA and unamended PDA (TABLE II). These differences, except those for conidium width, also differed significantly from PDA $(-0.4 \mathrm{MPa})$ to $\mathrm{KCl}$ medium $(-4.5 \mathrm{MPa})$. Although vesicle widths in $C$. floridanum were relatively constant, those of $C$. scoparium differed significantly on CLA, PDA and $\mathrm{KCL}$ medium $(-4.5 \mathrm{MPa})$.

There were no significant differences in conidium length and vesicle width in Cylindrocladiella camelliae on CLA and PDA, but significant differences did occur between PDA and KCL medium $(-4.5 \mathrm{MPa})$. Vesicle lengths were significantly longer between CLA and PDA, as well as between PDA and $\mathrm{KCl}$ medium $(-4.5 \mathrm{MPa})$.

FIGS. 5-7. Influence of osmotic potential of the growth medium in the percentage of the various vesicle-shape classes after 7 days at $25 \mathrm{C}$ with $12 \mathrm{~h}$ light per day. 5. Cylindrocladium scoparium. 6. Cylindrocladiella camelliae. 7. Cylindrocladium floridanum. Vesicles widest at base $=(\square)$; widest in the middle $=$ $(\nabla)$; widest at the apex with abrupt taper $=(0)$; widest at the apex with gradual taper $=(\bullet)$. Data at $-0.4 \mathrm{MPa}$ represents the osmotic potential for unamended PDA. Because only fungal material growing on carnation leaves was examined, no MPa value for CLA is given. 
TABLE I

CHLAMYDOSPORE FORMATION AND DOMINANT VESICLE SHAPE OF CYLINDROCLADIUM FLORIDANUM, C. SCOPARIUM AND CYLINDROCLADIELLA CAMELLIAE ON CARNATION-LEAF AGAR (CLA) AND KCL MEDIUM OF VARIOUS OSMOTIC POTENTIALS AT $25 \mathrm{C}^{\mathrm{a}}$

\begin{tabular}{|c|c|c|c|c|c|c|c|c|c|c|c|c|}
\hline \multirow[b]{3}{*}{ Species } & \multirow[b]{3}{*}{ Character } & \multicolumn{10}{|c|}{ Media } & \multirow[b]{3}{*}{-12.0} \\
\hline & & \multirow[b]{2}{*}{ CLA } & \multicolumn{9}{|c|}{ Osmotic potential $(\mathrm{MPa})$ of $\mathrm{KCl}$ medium } & \\
\hline & & & -0.4 & -0.8 & -1.3 & -1.8 & -2.2 & -3.6 & -4.5 & -6.9 & -8.9 & \\
\hline \multirow[t]{2}{*}{ C. floridanum } & Chlamydospores & - & 2 & 2 & 3 & 3 & 4 & 4 & 4 & 4 & - & - \\
\hline & Vesicles $^{c}$ & $C_{1}$ & $C_{1}$ & $C_{1}$ & $\mathrm{C}_{1}$ & $\mathrm{C}_{1}$ & $\mathrm{C}_{2}$ & $\mathrm{C}_{2}$ & $\mathrm{C}_{2}$ & - & - & - \\
\hline \multirow[t]{2}{*}{ C. scoparium } & Chlamydospores & - & 1 & 1 & 1 & 1 & 2 & 2 & 2 & 2 & 2 & - \\
\hline & Vesicles & B & A & A & A & B & B & B & $\mathrm{C}_{2}$ & - & - & - \\
\hline \multirow[t]{2}{*}{ C. camelliae } & Chlamydospores & - & 1 & 2 & 3 & 3 & 4 & 4 & 5 & 5 & 5 & - \\
\hline & Vesicles & B & B & B & B & B & B & $\mathrm{C}_{2}$ & $\mathrm{C}_{2}$ & - & - & - \\
\hline
\end{tabular}

${ }^{a}$ Cultures assessed 7 days after inoculation.

b $1=$ extensive; $2=$ medium; $3=$ fair $4=$ slight $5=$ few to none.

c $\mathrm{A}=$ widest at the bottom; $\mathrm{B}=$ widest in the middle; $\mathrm{C}_{1}=$ widest at apex with abrupt taper; $\mathrm{C}_{2}=$ widest at apex with gradual taper.

Although conidium width differed significantly on CLA and PDA, it did not differ significantly between PDA and $\mathrm{KCl}$ media.

Effect of osmotic potential on chlamydospore production. - In all isolates tested, chlamydospore production decreased, (in comparison to standard PDA) with a decrease in the osmotic potential of the $\mathrm{KCl}$ media (TABLE I). Chlamydo- spores did not form in the water agar on CLA plates, but did form on the leaf pieces.

\section{DISCUSSION}

These results show that vesicle shape is directly influenced by the osmotic potential of culture media. As cultures age, osmotic potentials of growth media tend to decrease, subsequently

TABLE II

AVERAGE CONIDIAL AND VESICLE DIMENSIONS OF CYLINDROCLADIUM FLORIDANUM, C. SCOPARIUM AND CYLINDROCLADIELLA CAMELLIAE ON CARNATION-LEAF AGAR (CLA), POTATO-DEXTROSE AGAR (PDA) AND KCL MEDIUM (KCL) AT $25 \mathrm{C}^{\mathrm{a}}$

\begin{tabular}{|c|c|c|c|c|c|c|c|c|c|c|c|c|}
\hline \multirow[b]{4}{*}{ Media } & \multicolumn{12}{|c|}{ Species } \\
\hline & \multicolumn{4}{|c|}{ C. floridanum } & \multicolumn{4}{|c|}{ C. scoparium } & \multicolumn{4}{|c|}{ C. camelliae } \\
\hline & \multicolumn{2}{|c|}{ Conidium } & \multicolumn{2}{|c|}{ Vesicle } & \multicolumn{2}{|c|}{ Conidium } & \multicolumn{2}{|c|}{ Vesicle } & \multicolumn{2}{|c|}{ Conidium } & \multicolumn{2}{|c|}{ Vesicle } \\
\hline & Length & Width & Length & Width & Length & Width & Length & Width & Length & Width & Length & Width \\
\hline CLA & 41.0 & 3.0 & 12.0 & 7.5 & 44.0 & 3.5 & 19.0 & 4.8 & 12.0 & 2.5 & 35.5 & 4.0 \\
\hline PDA $(-0.4)^{b}$ & 43.0 & 4.0 & 14.0 & 8.0 & 47.0 & 4.0 & 22.0 & 6.0 & 12.0 & 3.0 & 28.5 & 4.0 \\
\hline $\mathrm{KCl} \quad(-0.8)$ & 39.5 & 4.0 & 14.0 & 8.0 & 46.0 & 4.0 & 20.5 & 6.0 & 12.3 & 3.0 & 26.5 & 4.0 \\
\hline $\mathrm{KCl} \quad(-1.3)$ & 39.5 & 4.0 & 14.0 & 8.0 & 44.0 & 4.0 & 19.5 & 6.0 & 13.0 & 3.0 & 24.0 & 4.0 \\
\hline $\mathrm{KCl} \quad(-1.8)$ & 39.0 & 4.0 & 14.0 & 7.5 & 44.0 & 4.0 & 19.5 & 6.0 & 13.0 & 3.0 & 20.5 & 3.5 \\
\hline $\mathrm{KCl} \quad(-2.2)$ & 39.0 & 4.0 & 14.0 & 7.5 & 44.0 & 4.0 & 19.0 & 5.0 & 13.0 & 3.0 & 17.0 & 3.5 \\
\hline $\mathrm{KCl} \cdot(-3.6)$ & 36.0 & 3.8 & 12.5 & 7.0 & 42.5 & 4.0 & 19.0 & 4.5 & 13.0 & 3.0 & 17.0 & 3.5 \\
\hline $\mathrm{KCl} \quad(-4.5)$ & 33.0 & 3.8 & 11.0 & 7.0 & 41.0 & 4.0 & 12.5 & 3.5 & 13.0 & 3.0 & 15.0 & 3.5 \\
\hline $\begin{array}{l}\operatorname{LSD}^{\mathrm{c}} \\
\qquad(\mathrm{P}=0.001)\end{array}$ & 1.88 & 0.28 & 1.79 & 1.04 & 1.88 & 0.20 & 2.22 & 1.04 & 0.74 & 0.43 & 4.16 & 0.46 \\
\hline
\end{tabular}

a Conidial and vesicle dimensions were assessed 7 days after inoculation and represent an average of 180 measurements in $\mu \mathrm{m}$.

'Values in brackets denote the osmotic potential of the media in MPa.

c Means in the same column with a smaller difference than the LSD value (Least Significant Difference) are not significantly different $(\mathrm{P}=0.001)$. 

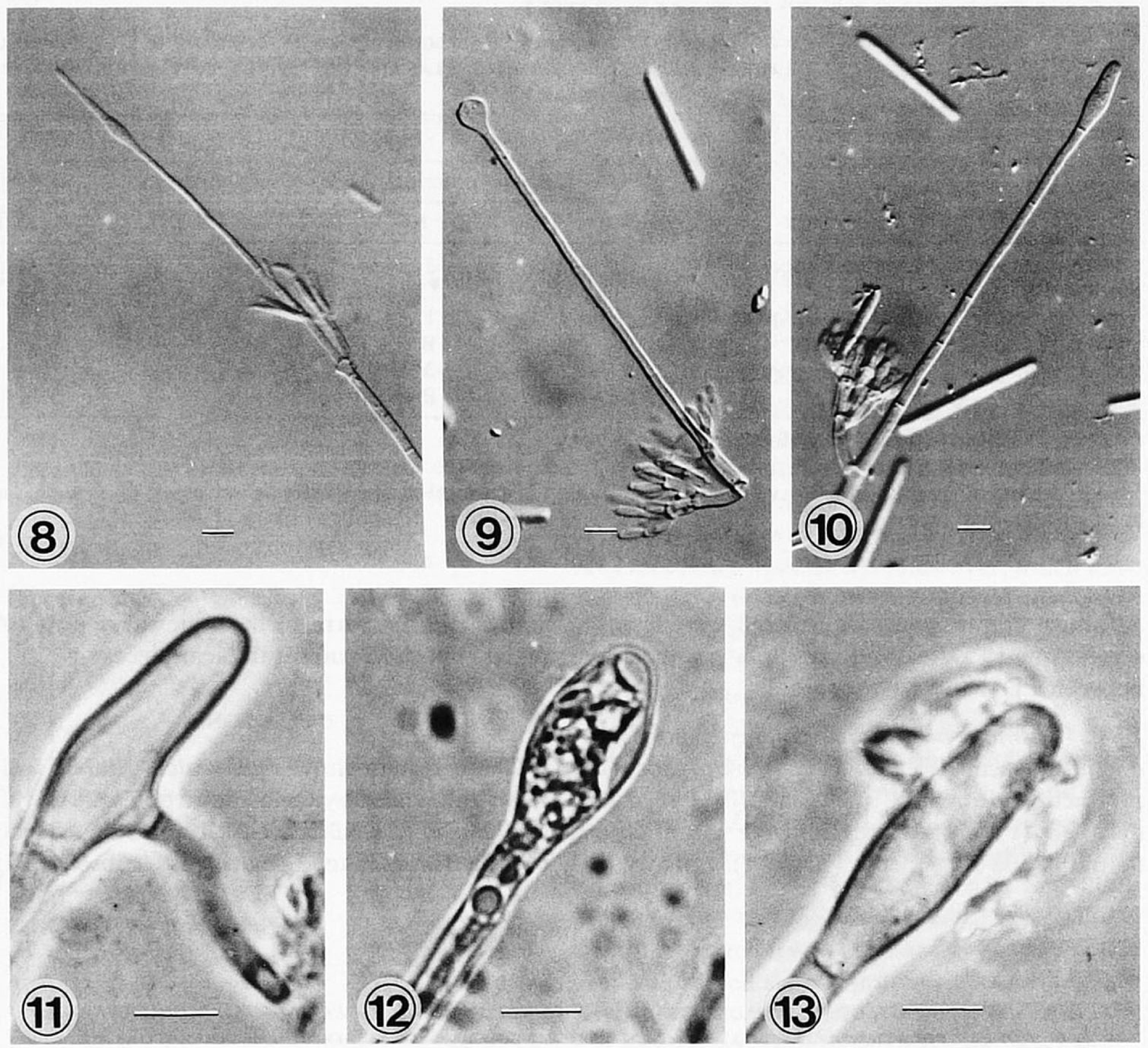

FIGs. 8-13. Conidiophores and vesicles. 8. Conidiophore of Cylindrocladiella camelliae with lanceolate vesicle on CLA. 9-13. Conidiophores and vesicles of Cylindrocladium floridanum and C. scoparium. 9. Conidiophore of $C$. floridanum with napiform vesicle on CLA. 10. Conidiophore of $C$. scoparium with obpyriform vesicle on PDA. 11. Germinating vesicle of $C$. scoparium. 12. Plasmolysed vesicle of $C$. scoparium on $\mathrm{KCl}$ medium ( $-4.5 \mathrm{MPa})$. 13. Mucilage exuded from a vesicle of $C$. scoparium (Scale bar $=10 \mu \mathrm{m}$ ).

influencing vesicle morphology. Characterization of species of Cylindrocladium and Cylindrocladiella based on vesicle shape, therefore, can not be achieved reliably without utilizing carefully characterized media. These observations compare favorably with those of Peerally (1991), who reported vesicle morphology to be reliable only in fresh cultures.

We recommend that $C y$ lindrocladium and $C y$ lindrocladiella are routinely characterized on CLA. Carnation leaves are well defined as a medium, support good sporulation, vesicle and perithecial formation, and are also routinely used in closely related genera such as Fusarium and Cylindrocarpon Wollenw. (Fisher et al., 1982; Samuels and Brayford, 1990). A standard incubation period of 7 days prior to making observations is advocated. This would reduce the negative effects of culture age on vesicle morphology. Measurements based solely on dried herbarium specimens of Cylindrocladium and Cylindrocladiella spp. should be treated with circumspection due to the lack of knowledge of conditions associated with sporulation. It is possible that there are countries where carnation leaves are not readily obtainable. We have tried to substitute 
other leaves (e.g., Eucalyptus spp.) but found that this resulted in completely different vesicle morphologies than those observed on CLA. Changes were more pronounced in Cylindrocladiella than in Cylindrocladium spp. and might be due to the different nature of the stipes in the two genera.

Although culture media had a minimal effect on conidial dimensions in Cylindrocladium, and even less effect in Cylindrocladiella, other authors (Alfieri et al., 1972; Zumpetta, 1976) found such variation to be more pronounced in multiseptate, large-conidial species of $C y$ lindrocladium. Furthermore, conidia of Cylindrocladium spp. commonly develop a distinct thickening or swelling at one end with age. This phenomenon could subsequently influence any conidial width measurements made from older cultures. This provides additional justification for standardization of media as well as that of incubation conditions used to grow cultures for identifications.

Vesicles in Cylindrocladium and Cylindrocladiella are not necessarily sterile, but can eventually develop further (Sobers and Seymour, 1967; Boesewinkel, 1982). The results of this study reconfirm these observations and have also shown that, with age, an additional septum can develop directly below the vesicle in Cylindrocladium and Cylindrocladiella. When the vesicle germinates or gives rise to a conidium (directly or via a phialide), another septum is frequently observed within the vesicle. Such secondary differentiation influences vesicle length and width, and suggests that only vesicles without any signs of further proliferation should be used for identifications. Furthermore, the data obtained in TABLE II showed vesicle width to be less variable than length, suggesting the former to be more reliable than the latter in identifications.

In $C$. scoparium and $C$. camelliae, vesicles changed from having their widest point at the base or middle to the vesicle apex at lower osmotic potentials. This observation suggests that a change in internal vesicle pressure leads to a deformation of the thin-walled vesicle. The correlation between the osmotic potential of the medium and the vesicle shape found in this study suggests that vesicle shape is influenced by turgor pressure. Ray et al. (1972) report that lower osmotic potentials can inhibit hyphal growth due to a loss of cell turgor. For fungal cells to maintain an influx of water, they must maintain a lower osmotic potential than that of the growth medium (Clipson and Jennings, 1990).
Cylindrocladium scoparium is more frequently associated with leaf spot symptoms than C. floridanum, which is primarily a root pathogen (Sobers and Seymour, 1967). Because the phylloplane is a much drier environment than that of the rhizosphere, the association of $C$. scoparium primarily with above-ground diseases might be related to its ability to grow at lower osmotic potentials than $C$. floridanum.

$C y$ lindrocladium scoparium and C. floridanum are very similar species that are not easily distinguished (Stevens et al., 1990). A distinct difference between the two species found in this study was the ability of $C$. scoparium to grow at lower osmotic potentials than C. floridanum. The possibility of using $\mathrm{KCl}$ medium to distinguish between these and other Cylindrocladium spp. warrants further investigation.

A decrease in sporulation, growth and vesicle formation on media with low osmotic potentials might explain why $C y$ lindrocladium and $C y l i n-$ drocladiella spp. are found only in areas with high humidity in South Africa. Furthermore, reduced chlamydospore production at lower osmotic potentials also indicates a decrease in the survival fitness of this group of fungi in arid areas. It would seem, therefore, that Cylindrocladium and Cylindrocladiella spp. lack the ability to survive and grow in dry climates.

The morphology of vesicles and conidia of $C y$ lindrocladium and Cylindrocladiella are subject to considerable variation depending on the osmotic potential of the media. Utilization of standardized media and incubation conditions, along with realization that different taxa exhibit differential responses to gradients in osmotic potential, should improve the reliability of measurements of these structures used in taxonomic characterization of species.

\section{LITERATURE CITED}

Alfieri, S. A., R. G. Linderman, R. H. Morrison, and E. K. Sobers. 1972. Comparative pathogenicity of Calonectria theae and Cylindrocladium scoparium to leaves and roots of azalea. Phytopathology 62: 647-650.

Boesewinkel, H. J. 1982. Cylindrocladiella, a new genus to accommodate Cylindrocladium parvum and other small-spored species of Cylindrocladium. Canad. J. Bot. 60: 2288-2294.

Booth, C., and J. S. Murray. 1960. Calonectria hederae Arnaud and its Cylindrocladium conidial state. Trans. Brit. Mycol. Soc. 43: 69-72.

Boyer, J. S. 1969. Measurements of the water status of plants. Annual Rev. Pl. Physiol. 20: 351-364. 
Bugbee, W. M. 1962. Studies on the epidemiology of Cylindrocladium scoparium Morgan. M.S. Thesis, Univ. of Minnesota, St. Paul. 46 pp.

Clipson, N. J. W., and D. H. Jennings. 1990. Role of potassium and sodium in generation of osmotic potential of the marine fungus Dendryphiella salina. Mycol. Res. 94: 1017-1022.

El-Gholl, N. E., J. W. Kimbrough, E. L. Barnard, S. A. Alfieri, and C. L. Schoulties. 1986. Calonectria spathulata sp. nov. Mycotaxon 26: 151-164. , R. M. Leahy, and T. S. Schubert. 1989. Cylindrocladium leucothoeae sp. nov. Canad. J. Bot. 67: 2529-2532.

Fisher, N. L., L. W. Burgess, T. A. Toussoun, and P. E. Nelson. 1982. Carnation leaves as a substrate and for perserving cultures of Fusarium species. Phytopathology 72: 151-153.

, W. F. O. Marasas and T. A. Toussoun. 1983. Taxonomic importance of microconidial chains in Fusarium section Liseola and effects of water potential on their formation. Mycologia 75: 693-698.

Hunter, B. B., and H. L. Barnett. 1978. Growth and sporulation of species and isolates of Cylindrocladium in culture. Mycologia 70: 614-635.

Morgan, A. P. 1892. Two new genera of Hyphomycetes. Bot. Gaz. 17: 190-192.

Nelson, P. E., L. W. Burgess, and B. A. Summerell. 1990. Some morphological and physiological characters of Fusarium species in sections Liseola and Elegans and similar species. Mycologia 82: 99-106.

, T. A. Toussoun, and W. F. O. Marasas. 1983. Fusarium species: an illustrated manual for identification. Pennsylvania State University Press, University Park, Pennsylvania. 193 pp.

Peerally, M. A. 1973. Calonectria colhounii sp. nov., a common parasite of tea in Mauritius. Trans. Brit. Mycol. Soc. 61: 89-93.

- 1991. The classification and phytopathology of Cylindrocladium species. Mycotaxon 40: 323366.
Prior, B. A. 1979. Measurement of water activity in foods: a review. J. Food Prot. 42: 668-674.

Ray, P. M., P. B. Green, and R. Cleland. 1972. Role of turgor in plant cell growth. Nature 239: 163164.

Robinson, R. A., and R. H. Stokes. 1959. Electrolite solutions. 2nd ed. Butterworth and Co., London. $571 \mathrm{pp}$.

Rossman, A. Y. 1983. The phragmosporous species of Nectria and related genera. Mycol. Pap. 150: 1164.

Samuels, G. J., and D. Brayford. 1990. Variation in Nectria radicicola and its anamorph, Cylindrocarpon destructans. Mycol. Res. 94: 433-442.

Schoulties, C. L., N. E. El-Gholl, and S. A. Alfieri, Jr. 1982. Cylindrocladium spathiphylli sp. nov. Mycotaxon 16: 265-272.

Snell, W. H., and E. A. Dick. 1957. A glossary of mycology. Harvard University Press, Cambridge, Massachusetts. $171 \mathrm{pp}$.

Sobers, E. K. 1968. Morphology and host range of Cylindrocladium pteridis. Phytopathology 58: 1265-1270.

—, and C. P. Seymour. 1967. Cylindrocladium floridanum sp. $\mathrm{n}$. associated with decline of peach trees in Florida. Phytopathology 57: 389-393.

Stevens, C., M. A. Palmer, A. Y. Tang, and R. E. McRoberts. 1990. Use of aminopeptidase substrate specificities to identify species of $C y$ lindrocladium in Wisconsin nurseries. Mycologia 82: 436-443.

Sutton, B. C. 1980. The Coelomycetes. Commonwealth Mycological Institute, Kew, Surrey, England. $696 \mathrm{pp}$.

Zumpetta, G. M. 1976. An electrophoretic study of the proteins of the genus Cylindrocladium as a possible taxonomic tool. M.S. Thesis, California State College, Pennsylvania. 91 pp.

Accepted for publication February 25, 1992 